ARTÍCULO

\title{
La voz de la mujer afro como medio de preservación de la herencia cultural raizal en el Archipielago de San Andrés, Santa Catalina y Providencia: aproximaciones desde la etnoeducación, la pedagogía crítica y la comunicación popular
}

Diego Fernando Peña Garnica

\section{RESUMEN}

El documento ofrece un recorrido histórico-cultural entorno a la comunidad raizal del Archipiélago de San Andrés, Providencia y Santa Catalina en el Caribe Colombiano a partir del desarrollo de un estudio cualitativo de carácter descriptivo desde el que se implementó la revisión documental y literaria como método de investigación. En sus apartes, se abordan los diferentes procesos sociales y comunitarios que, desde las perspectivas críticas, contribuyen al empoderamiento y formación de la identidad étnica sanandresana gracias al aporte de la mujer afro como garante del patrimonio inmaterial de su contexto y de su legado africano. En consecuencia, la revisión del rol de las narradoras orales y la aproximación de su labor hacia un diálogo con las prácticas de la pedagogía liberadora y la comunicación popular, permitirán reconocer el valor de una lucha contrahegemónica librada por generaciones de marginados que se reivindican a través del poder la palabra hablada.

PALABRAS CLAVE

comunicación popular; etnoeducación; mujer afro; oralidad; San Andrés.

'Corporación Universitaria Minuto de Dios, Bogota, Colombia. 
THE VOICE OF AFRO WOMEN AS A MEANS OF PRESERVING

THE RAIZAL CULTURAL HERITAGE IN THE ARCHIPELAGO

OF SAN ANDRÉS, SANTA CATALINA, AND PROVIDENCIA:

APPROACHES FROM ETHNO-EDUCATION, CRITICAL PEDAGOGY, AND POPULAR COMMUNICATION

\begin{abstract}
The document offers a historical-cultural tour around the Raizal community of the Archipelago of San Andrés, Providencia, and Santa Catalina in the Colombian Caribbean from the development of a descriptive qualitative study from which the documentary and literary review was implemented as a research method. In its sections, the different social and community processes that, from critical perspectives, contribute to the empowerment and formation of the San Andrés ethnic identity thanks to the contribution of Afro women as guarantors of the intangible heritage of their context and their African legacy, are addressed. Consequently, the review of the role of oral storytellers and the approach of their work toward a dialogue with the practices of liberating pedagogy and popular communication, will allow us to recognize the value of a counter-hegemonic struggle waged by generations of marginalized people who claim their rights through the power of the spoken word.
\end{abstract}

KEYWORDS

popular communication; ethnoeducation; Afro woman; orality; San Andrés.

\title{
A VOZ DA MULHER AFRO COMO MEIO DE PRESERVAR O PATRIMÔNIO CULTURAL RAIZAL NO ARQUIPÉLAGO DE SAN ANDRÉS, SANTA CATALINA E PROVIDÊNCIA: ABORDAGENS DE ETNO-EDUCAÇÃO, PEDAGOGIA CRÍTICA E COMUNICAÇÃO POPULAR
}

\section{RESUMO}

O documento oferece um passeio histórico-cultural pela comunidade Raizal do Arquipélago de San Andrés, Providencia e Santa Catalina no Caribe colombiano a partir do desenvolvimento de um estudo qualitativo descritivo a partir do qual a revisão documental e literária foi implementada como um método de pesquisa. Em suas seções, são abordados os diferentes processos sociais e comunitários que, a partir das perspectivas críticas, contribuem para o fortalecimento e formação da identidade étnica de San Andrés graças à contribuição da mulher afro como garantidora do patrimônio imaterial de seu contexto e de seu legado africano. Consequentemente, a revisão do papel dos contadores de histórias orais e 
a abordagem de seu trabalho em direção a um diálogo com as práticas da pedagogia libertadora e da comunicação popular, nos permitirá reconhecer o valor de uma luta contra-hegemônica travada por gerações de pessoas marginalizadas que reivindicam seus direitos através do poder da palavra falada.

\section{PALAVRAS-CHAVE}

comunicação popular; etnoeducação; mulher afro; oralidade; San Andrés.

\section{INTRODUCCIÓN}

Las dinámicas globalizadoras que rigen la contemporaneidad de las naciones y sus ciudadanías constituyen una plataforma desde la que se favorece la proliferación simultánea de procesos sincréticos entre comunidades hasta hace poco inconexas. La resignificación de estos escenarios en donde convergen diferentes perspectivas desde lo económico, político, cultural y social sugiere que además del ideal cooperativista e integrador del intercambio favorable a todas las partes, las relaciones de poder que se constituyen a partir de estas proximidades tienden a decantar en etapas posteriores de aculturación y transculturación (Pérez-Brignoli, 2017).

En este sentido, las realidades de la comunidad raizal del Archipiélago de San Andrés, Providencia y Santa Catalina en el actual territorio de ultramar colombiano, son evidencia de las consecuencias de una política histórica orientada hacia la homogenización cultural de la comunidad nativa y el aprovechamiento de la institucionalidad estatal para el desarrollo del comercio y de la industria turística nacional, lo que con el paso del tiempo, profundizaría el detrimento de los valores identitarios de esta población y de su herencia ancestral rastreable desde el África.

En la versión más reciente del conflicto histórico por el dominio de estos territorios caribeños se involucran los gobiernos de Colombia y Nicaragua, razón por la cual, a principios del siglo XX desde Bogotá y Managua se desplegaron diversas estrategias diseñadas para favorecer el proceso de unificación con el territorio continental de ambos países. Del lado colombiano, la implementación de un modelo de educación nacionalista y el afianzamiento del Archipiélago como referente económico a raíz de su apertura comercial en la década de 1950; constituyen el punto de partida en un proceso de colombianización en el que resaltan la imposición del español como lengua oficial de los territorios anglófonos y el asentamiento masivo de comerciantes colombianos continentales en la isla.

En contraste, el ejercicio de preservación y transmisión cultural en el que las mujeres sanandresanas articulan la práctica etnoeducativa con la oralidad de sus propias tradiciones se concibe como una manifestación de resistencia contrahegemónica propia de contextos comunicativos que buscan hacer frente al efecto de las imposiciones extranjeras desde lo popular e identitario; por esta razón, el desarrollo de la revisión alrededor del fenómeno sincrético y transcultural en el Archipiélago expone un recorrido en el que se describe la relación histórica de las comunidades 
que coexisten en su geografía, a la vez que resignifica el aporte de la tradición oral raizal como escenario natural para la visibilidad de los liderazgos feministas locales.

\section{CONTEXTUALIZACIÓN HISTÓRICA Y CULTURAL}

Posterior a su etapa precolombina, Latinoamérica se concibe como el punto de convergencia para las culturas nativas americanas, europeas y africanas; quienes contribuyeron a través de sus lenguajes, tradiciones e imaginarios a la configuración de un nuevo escenario sociocultural consolidado durante el proceso de colonización en América a partir de la primera mitad del siglo XVI. Este proceso transformaría al continente en receptor de costumbres importadas por europeos y africanos, lo que decantaría en una mezcla de cosmovisiones marcadas por las relaciones de poder que establecerían como autoridad hegemónica a los europeos por encima de la voluntad y los intereses de las demás culturas.

Las consecuencias de las mediaciones interculturales influenciadas por este poder hegemónico aportarían a la constitución de una sociedad pigmentocrática (Lipschutz, 1975), que relegó al pueblo negro secuestrado en África a cumplir con una condena esclavista impuesta por el hombre blanco en el nuevo territorio y a los nativos americanos a contribuir como servidumbre en favor de los intereses europeos. Si bien en gran parte de la América continental esta estructura de poder se consolidó bajo las directrices de la corona española, en el caso de la región $\mathrm{Ca}$ ribe y como consecuencia de su ubicación geográfica; en las islas de San Andrés, Providencia y Santa Catalina, la incidencia de culturas de origen europeo (ingleses, franceses, holandeses y españoles) junto con la llegada de los esclavos africanos procedentes de otras colonias en el Caribe, configurarían un entorno diverso con una marcada diferencia cultural en relación con las dinámicas que se desarrollaban durante la colonia en la plataforma continental. En las islas del Caribe, a pesar de las características de cada territorio, el modelo era el mismo:

el pequeño grupo de los blancos plantadores se orientaba a Europa, porque se veían su domiciliado en las islas sólo como pasajero, mientras la mayoría de los africanos esclavizados trataba de crear nuevas formas durables intentadas de continuar una pertenencia en su nuevo mundo. (Leipold, 2002, p. 61)

Por tanto, los descendientes de los plantadores y esclavos provenientes de Jamaica que poblaron las desiertas islas al final del siglo XVIII pudieron conservar su identidad cultural, a pesar de que eran ciudadanos de un país abrumadoramente católico y en buena medida culturalmente hispánico. (Meisel-Roca et al., 2016, p. 19)

En su primera etapa, la llegada de ingleses y holandeses al Archipiélago estaría motivada por la facilidad con la que era posible planear y ejecutar asaltos a los galeones españoles que navegaban por el Caribe desde las playas seguras de las islas. "Para estas dos naciones, su presencia fue útil para la ampliación política de sus objetivos; desafiar la reivindicación española de todas las Américas y en parti- 
cular, las restricciones a otros que realizan comercio en la zona” (Ross, 2007, p. 7). Sin embargo, en oleadas poblacionales posteriores, los movimientos migratorios y el asentamiento de estas comunidades son descritos como complemento a las rutas identitarias de la comunidad raizal, compuestas ademas de los aportes de las culturas europea y africana; por la influencia de las comunidades indígenas pertenecientes a la cultura Mikito en las costas nicaragüenses de América Central y al proceso de colombianización rastreable a partir del Congreso de Cúcuta de 1822 que adheriría las islas a la Federación de la Gran Colombia. Sobre este hecho, Ross (2007) retoma a Bill Francis (1988); manifestaría: "Ellos (Colombia) han torcido nuestra historia y enseñan a nuestros hijos que sus bisabuelos pidieron libremente formar parte de la Gran Colombia. Eso no es cierto, nada se ha hecho libremente en esta isla" (Ross, 2007,p.13). Lo que refiere al efecto generado en la población del archipiélago como consecuencia de las políticas nacionalistas adoptadas por los gobiernos de Colombia y Nicaruagua para minimizar la influencia del otro en la región.

Con la posterior promulgación del Decreto No 2966 (Colombia, 1953) por parte del Gobierno Colombiano que convertiría el territorio del Archipiélago en puerto libre; la importación de artículos exentos del pago por derechos de aduana en la isla desencadenaría una intensa ola migratoria compuesta en su mayoría por "turistas provenientes de las diversas regiones de la Colombia continental, así como por comerciantes árabes y judíos que se establecieron en el territorio de ultramar" (Meisel-Roca et al., 2016, p. 19). Esta medida contribuiría al incremento poblacional de las comunidades no raizales en la isla, fenómeno que afectaría a largo plazo y de manera negativa la realidad social, económica y cultural de las comunidades nativas que experimentarían el volcamiento de sus actividades cotidianas hacia el fortalecimiento del comercio y el estímulo de las actividades que se derivan de él. "La agricultura y la pesca, principales actividades generadoras de ingresos de la comunidad raizal hasta ese momento, perdieron relevancia, y aquellos pocos que manejaban el comercio fueron desplazados por los nuevos empresarios" (Yabrudy, 2011, p. 250).

Por otro lado, como consecuencia del modelo de educación amparado en la fe católica e instaurado en las islas por el gobierno colombiano desde principios del siglo XX, la historicidad de las comunidades raizales enfrentó la amenaza a su tradición y etnicidad desde el desarrollo de prácticas represoras y hegemónicas orientadas hacia la unificación cultural de los habitantes del archipiélago "en una sola lengua: el español; una sola religión: la católica, y una sola historia patria, ignorando así la lengua, la historia y demás manifestaciones culturales propias de las islas" (Botero Mejía, 2007, p. 277). E1 efecto de estas políticas en las dinámicas cotidianas de los sanandresanos se manifestó a través de exigencias discriminatorias como la conversión religiosa del protestantismo al catolicismo como requisito para ocupar cargos públicos en la isla y obtener beneficios de la institucionalidad colombiana. A su vez, la prohibición del uso de su propia lengua en contextos de formación académica y la discriminación salarial en comparación con las comunidades extranjeras, terminarían por configurar un escenario sociocultural compuesto por una elite de comerciantes extranjeros y algunos raizales pudientes dueños de tierras y beneficiarios de la renta de sus terrenos; por otro 
lado, la clase raizal baja se constituye por quienes no lograron integrarse a las nuevas prácticas comerciales del Archipiélago y por quienes no poseen tierras debido en algunos casos "a malas prácticas de inmigrantes, quienes, aprovechando el desconocimiento del idioma español (idioma en el cual se elaboraban los documentos de compraventa y escrituraciones), despojaron de sus tierras a más de un nativo" (Yabrudy, 2011, p. 251).

Sin embargo, la proliferación de movimientos contrahegemónicos y de resistencia surgidos como respuesta a la imposición de políticas centralistas en las islas se deben inicialmente al nativo raizal que "descubre su propia identidad cuando se transforma en minoría” (Valtolina, 2019, p. 36), pero también, a la capacidad de este individuo para transmitir el legado de su cultura a las nuevas generaciones de sanandresanos raizales. Gracias al

interés por darle valor al legado cultural de comunidades colonizadas y sometidas por occidente y sus nociones de desarrollo moderno, se reconocen las contribuciones de los indígenas, de los migrantes y las capas populares urbanas, y también de mujeres, homosexuales y otros grupos excluidos. (Canclini, 1999, p. 20)

de los que también hace parte la comunidad raizal de las islas caribeñas y por lo cual el aporte etnoeducativo desde su oralidad, adquiere especial relevancia en cuanto contribuye a la construcción de una identidad étnica creole desde las narrativas propias de los isleños y a través del rol de la mujer como narradora oral y referente cultural en una comunidad que "se constituye como minoría en su propio lugar de origen”. (Patiño, 2011, p. 121)

\section{CORPOREIDAD, ORALIDAD Y ESCLAVITUD}

La legislación de la corona española para la América colonial de mediados del siglo XVI alrededor a la regulación de los derechos y deberes de los esclavos se consolidó de forma paulatina como un mecanismo de control generalizado que buscaba garantizar el acceso de las elites españolas a la mano de obra y capacidad productiva de las poblaciones afro y criollas compuestas tanto por hombres libes como por personas cautivas.

Las dinámicas de las relaciones de poder entre esclavos y esclavistas durante la colonia en América y el Caribe giran en torno a la concepción del cuerpo humano como un bien económico en la medida en que la potencia física del hombre africano era explotada con fines productivos en latifundios dedicados al cultivo de la caña; mientras que, el cuerpo de la mujer afro se preciaba por su capacidad reproductiva, lo que se traducía en el incremento de esclavos al servicio de los intereses del hombre blanco. Al respecto, lo retoma en el abordaje de las relaciones cuerpo - mundo y cuerpo - otredad (Xolocotzi y Gibu, 2014); propone un escenario de discusión alrededor del sentido que se le asigna a la dimensión corpórea de los sujetos, a partir 
de su ubicación contextual/histórica y de las dinámicas biopolíticas que surgen como consecuencia de las relaciones de poder entre ellos.

A inicios del siglo XVII, la estructura demográfica del Archipiélago consistía en una comunidad puritana de 500 hombres y 40 mujeres provenientes de Inglaterra, quienes se establecieron en Providencia junto con los primeros grupos de esclavos que llegaron en 1633 para apoyar la agricultura tropical y la construcción de fortificaciones (Ross, 2007). "En ese contexto social, el trabajo y el cuerpo de la mujer negra era uno de los pilares de la vida privada. La africana era considerada un medio para procrear mestizos, justificado por razones económicas" (de la Rocha Penna, 2014, p. 6).

La particularidad histórico-situacional de las islas permite reconocer en su territorio un escenario de convergencia y manifestación de los efectos producidos tras las interacciones del cuerpo, el mundo y el otro en un contexto de esclavitud y colonialismo, lo cual, se ve reflejado en la jerarquización racial de las sociedades americanas del siglo XVI y desde las perspectivas fenomenológicas del yo de Husserl, en el consecuente distanciamiento de las nociones del cuerpo orgánico en el que se "distingue el carácter vinculante entre la realidad espiritual y material. A diferencia del cuerpo físico, relativo al espacio y a la realidad natural o animal del hombre" (Butiérrez, 2020, p. 83).

En este sentido, el abordaje de las relaciones del cuerpo con el mundo y con el otro conducen hacia la contextualización del cuerpo propio como mecanismo de percepción del entorno, lo que también incluye la idea de otredad a partir de su reconocimiento empático/analógico y sugiere un vínculo entre lo espiritual y lo humano desde el que es posible diferenciar en paralelo el factor animal.

En el Caribe colonial, la lectura del modelo esclavista desde las perspectivas abordadas plantea la capacidad del hombre blanco para reconocerse a sí mismo en la interpretación de los demás a partir de la identificación de potenciales rasgos comunes como la lengua, religión, o tradiciones y comportamientos particulares; en consecuencia, la aparente proximidad de lo espiritual, lo religioso y lo humano sugeriría una conexión empática con los demás hombres blancos con quienes comparte algún factor común que los define como elementos hegemónicos. En contraste, la lectura de la diferencia cultural y religiosa característica de este periodo supone una interpretación del cuerpo del esclavo desde lo carente de espíritu, alejado de lo humano y reducido a un escenario limitado por su dimensión material y anímico-animal.

Para la comunidad esclava secuestrada en territorio americano, el efecto de estas tensiones se manifestaría a partir de la imposición de nuevas prácticas culturales y religiosas que terminarían por ajustar la identidad afro-ancestral a los intereses y creencias de sus amos europeos. En las islas, a finales de siglo XIX, con la muerte de Eliza O'Neill, primera esposa del pastor bautista Philipp Livingston, el segundo matrimonio lo uniría a la negra Josephine Pomaire, ama de cría de su hija. "Cuando pastor Livingston tomaba ella por su esposa en 1865, la relación daba mucho motivo para chismes y calumnia dentro de la sociedad blanca de la isla" (Leipold, 2002, p. 34). El referente del matrimonio permite establecer que el ama de cría, lejos de su tradición africana, fue adoctrinada por la iglesia protestante, pero a pesar 
de esto, no se eximió de ser asumida por la hegemonía desde la conceptualización limitada de su cuerpo físico.

Después de las tensiones entre europeos como resultado de los ataques ingleses desde el Archipiélago a barcos españoles que cruzaban el Caribe, "en 1641, una fuerza española de 600 soldados liderada por Francisco Días de Pimienta y un sacerdote católico llegado de Cartagena vinieron con órdenes para 'limpiar' las islas. La guarnición pronto se rindió y hubo pocas muertes” (Ross, 2007, p. 8), lo que significó la imposición de la fe católica a los sobrevivientes ingleses de fuertes raíces protestantes. Desde las perspectivas de las comunidades de esclavos, la relación con españoles o ingleses era la misma, por lo que más allá de la imposición religiosa, las acciones militares no representaron ningún cambio relevante para el rol que desempeñaban durante este periodo.

Sin embargo, en el marco de estas mediaciones condicionadas por la tradición hegemónica europea, el cuerpo de la mujer africana era concebido también como garantía de tolerancia racial, constituida a través de su sexualidad; por lo que el nacimiento de hijos mestizos entre madres africanas y padres europeos aproximaría sus labores hacia el cuidado de los hijos de sus amos junto con los propios.

Pero esa relación se basó en un doble prejuicio racial y machista. El conquistador o mata o reduce a la esclavitud el varón indio o negro; y toma posesión del cuerpo de la india y de la negra. El dominio del cuerpo de la mujer india o negra es parte de una cultura que se basa en el dominio del cuerpo del hombre indio o negro. Por la esclavitud, estaban asociados a la materia y al mundo material, como objetos: los cuerpos para el trabajo y para el goce del propietario de la vida esclava. (de la Rocha Penna, 2014, p. 6)

El abordaje reflexivo en torno a la corporeidad y esclavitud femenina permite reconocer en la mujer afro la doble condición de vulnerabilidad que se configura alrededor de su rol en el contexto del nuevo mundo, que, además de los padecimientos propios de la esclavitud motivada por fines de producción económica, eran sometidas a prácticas esclavistas de carácter sexual y a cumplir con labores de nodriza al servicio de los hijos de sus amos; ambas actividades determinadas por su condición biológica de mujer.

Como consecuencia de la promulgación de Las Siete Partidas (Castella, 1807), el poder del establecimiento colonial español en el continente americano fortaleció el control y dominio de los amos europeos sobre la sexualidad, la maternidad y los hijos de sus esclavas. En este sentido, se determinó una línea hereditaria de la condición esclava a partir de la condición de la madre, es decir: "Es esclavo el nacido de madre esclava, aunque el padre sea libre, y es libre el hijo de madre libre, aunque el padre no lo sea" (León, 2008, p. 139). En países como Costa Rica, el desarrollo de este tipo de prácticas favoreció la normalización de la explotación sexual y económica de las mujeres esclavas durante el siglo XVIII; producto de ello, se asume que el yugo de este sector poblacional impulsó el crecimiento económico y productivo del territorio a cambio del cuidado y protección ofrecido por el grupo hegemónico dominante. 
Si bien, la revisión histórica de la legislación esclavista permite identificar apartados en los que se establecen los parámetros normativos para la posesión y protección de las mujeres esclavas. En la práctica, muchos de los casos de abuso y maltrato de los amos a las mujeres de su servidumbre se relacionan de forma directa o indirecta con la explotación de sus cuerpos en su dimensión sexual y reproductiva, ya que además de las violaciones, la prostitución forzosa también resultaba frecuente, por lo que, "las imágenes y estereotipos creados por los amos sobre las esclavas y sus comportamientos fueron claves para justificar su dominación y reforzar la explotación sexual" (León, 2008, p. 146).

En cuanto a las disposiciones respecto a la vida reproductiva de las esclavas, la norma facultaba a los esclavistas el desarrollo de actividades comerciales en las que los hijos de las mujeres de su servidumbre eran expuestos como bienes de consumo (Jaramillo y Ortiz, 2011), sin tomar en consideración los lazos del núcleo filial de los infantes. El nivel de deshumanización de los cuerpos alcanzado en este contexto mercantil se vería reflejado de igual manera en prácticas como las marcas a fuego en la piel de los esclavos para la identificación de sus propietarios; por lo que además de la incertidumbre de poder crecer junto sus madres, los vejámenes físicos eran infringidos a los cuerpos desde corta edad como recordatorio del poder que los subyugó. "Pedro y Juana de Rivera, en mancuerna comercial le vendieron a Pedro Vargas un esclavo criollo, Juan de 13 años con dos letreros en el rostro que dicen Juan Yáñez" (Montoya, 2015, p. 94), nombre de su anterior dueño.

No obstante, el rol de muchas de estas mujeres que se vieron obligadas a renunciar a la crianza de sus propios hijos, fue reasignado a la asistencia permanente de los infantes de sus amos, bajo la denominación de ama de cría. En consecuencia, las implicaciones de la relación nodriza-niños terminarían por generar un espacio de visibilidad para la voz de la mujer afro y su capacidad narrativa en el marco de la crianza y a través de la consolidación del vínculo afectivo que se desarrollaba entre las amas de cría, sus propios hijos y los hijos de sus amos. Este lazo resultaría "determinante para la formación de su personalidad, ya que esa intimidad - hoy lo sabemos - se queda indeleble en el más profundo y decisivo de la psique con todas sus implicaciones psicológicas y psicoanalíticas" (de la Rocha Penna, 2014, p. 6).

La lectura en torno a la proximidad afectiva de los niños blancos y sus nodrizas permite dimensionar las dinámicas sincréticas que se desprenden de la oralidad de las mujeres afro y explica cómo desde las etapas de lactancia y crianza las esclavas influyeron culturalmente en la constitución del nuevo mundo a través de su voz. Morlachetti (2011) rescata la manera en que las amas de cría mecían a sus amos en los brazos mientras cantaban "A-ro-ró" para facilitarles conciliar el sueño. Esta expresión de origen africano deriva de la mala pronunciación del término "dormir" que era usado como "romi" y se simplificó hasta "ro". "De ahí, pues, que, en su dulce forma interpretativa, ' $A$-ro-oró significa 'a dormir, dormir'o 'duérmete" (Morlachetti, 2011, p. 44). La naturaleza de este espacio de crianza e intimidad permite visibilizar el legado y tradición cultural de la población esclava desde la perspectiva de la mujer; algo sin precedentes durante el periodo esclavista continental si se toma en cuenta que el contexto sociocultural de la colonia en América y el Caribe desconocía la voz no solo de la mujer afro, sino también de las mujeres blancas, indígenas y mestizas, 
en gran parte como resultado de la minimización del rol femenino en la mitología cristiana impuesta por el hombre blanco europeo en el nuevo continente.

El Antiguo y el Nuevo Testamento dan fe de todo lo que aconteció en el mundo desde su milagrosa creación por una energía única, masculina por demás Dios. De cómo fue todo, desde la primera mujer, el primer parto y el porqué del dolor, dan fe los hombres. Ninguna santa opina, ninguna mujer, ni aun la que sintió los dolores. Si desde entonces se le negó a la mujer el derecho al testimonio, siendo blanca, porque desde el punto de vista sexista racial Eva lo era, cómo hacerlo la mujer negra, tenida como algo menos que una mujer, si acaso un animal especial con algunas atribuciones humanas. (Herrera, 2011, p. 37)

El adoctrinamiento cultural puritano y católico en la isla obstaculizó a los raizales el reconocer de su relación directa con África (Leipold, 2002). Sin embargo, como respuesta a esta marginalidad, la historicidad colonial de la cultura afro marcada por el estigma de su condición esclava estimuló el desarrollo de prácticas comunicativas alternas constituidas basadas en el valor de la palabra hablada, desde su propia oralidad, lo que facilitó la transmisión de valores e identidad étnica a través de canales como el canto, el baile y la gastronomía, además de otras expresiones que configurarían la ruta de comunicación entre generaciones de isleños unidos por su herencia africana. En la actualidad, la oralidad de los raizales aún es la herramienta natural para la transmisión de valores culturales en comunidades como la del Archipiélago, debido a que "gran parte de los raizales, nacidos después de la apertura del puerto libre, no escribe en inglés y tampoco existe en estas islas una tradición de escritura en creole (lengua criolla de base léxica inglesa) ni en inglés caribeño" (Pomare y Dittman, 2000, p. 10). Lo que hace que, a pesar de las políticas alfabetizadoras para estimular la práctica escritural en la comunidad raizal, "en términos generales, los niños, niñas y jóvenes isleños afirman enfáticamente que no les gusta escribir en ninguna lengua" (Botero Mejía, 2007, p. 285).

$\mathrm{El}$ aporte a las dinámicas de resistencia cultural que se rastrean desde el rol de la mujer afro en contextos de esclavitud y colonialismo se enriquece a partir de la experiencia individual de cada mujer, pero se colectiviza en la medida en que sus saberes y tradiciones se replican desde mucho antes de la época de la colonia y aún hoy son sinónimo de resistencia cultural y de la identidad raizal sanandresana.

Las mujeres esclavas desempeñaron en la agencia de su libertad y la de los miembros de su familia, un rol activo movilizando todo un conjunto de maniobras y saberes que son alimentados por su experiencia personal como mujeres, como esclavas y como parte de una dinámica social determinada, que les permitió manejar relaciones, establecer contactos y hacer uso de herramientas discursivas y recursos institucionales a partir de los cuales construir con éxito estrategias de libertad. (Chaves, 1998, p. 4)

$\mathrm{Al}$ prescindir de la escritura, las prácticas ancestrales de la comunidad raizal y sus valores culturales "se aprenden de generación en generación debido a que cada 
uno de ellos puede ser traducido a un símbolo, y transmitido para que - mediante el lenguaje - las nuevas generaciones lo memoricen y lo manejen" (Arocha, 2000, p. 2). La idea de construir de forma permanente una identidad narrativa raizal en el Archipiélago es descrita por Ricoeur (2006), según Cuevas (2021), como una tarea que "no es dada previamente ni constituida en el vacío ni en forma fija del conocimiento, sino que se trata de una identidad que se construye a través de un proceso, es por lo tanto,una identidad móvil y dinámica" (Cuevas, 2021, p. 56). En otras palabras, la naturaleza del ejericio identitario en estas comunidades se desarrolla de manera permanente y responde de forma directa las particularidades del contexto en el que se ejecuta.

El oficio de la pesca, en particular, es aprendido gracias a la experiencia compartida de pescadores mayores, quienes ofrecen consejos a los más jóvenes con la intención de desarrollar en ellos las destrezas requeridas para este labor artesanal; por otra parte, la mujer raizal desde el rol de narradora oral, contribuye a la transmisión de "conocimiento sobre las ciencias de la naturaleza, la religión, la sabiduría, los saberes y oficios, la recreación y los valores, al igual que de la literatura, la historia, la música y la danza de las islas" (Botero Mejía, 2007, p. 283), pues como en el contexto de la colonia en América, "en el archipiélago las mujeres raizales asumen una mayor responsabilidad en conservar, recrear y dar cohesión a su cultura, gracias a ellas se mantiene especialmente la gastronomía y la lengua nativa de los isleños" (Patiño, 2011, p. 122).

Durante el siglo XIX, después de la abolición de la esclavitud en el Archipiélago, el deterioro de la infraestructura disponible para el cultivo de caña y el eventual abandono de las plantaciones traerían como consecuencia el inebitable abocamiento a la misería de las comunidades afro, quienes, encontrarían en la producción y exportación de coco hacia Jamaica, México y EEUU, una economía alternativa que estrecharía lazos entre las culturas raizales y norteamericanas. Por lo que "las islas no sufrieron el declive experimentado por muchos de sus compañeras Islas del Caribe que antes dependían del comercio de las plantaciones" (Ross, 2007, p. 16). Las dinámicas socioculturales que se desprendieron como consecuencia de estas relaciones comerciales se evidenciarían durante la etapa de imposición cultural implementada por la Nueva Granada y el posterior Gobierno de Colombia.

\section{ETNOEDUCACIÓN Y COMUNICACIÓN POPULAR}

La aproximación conceptual a las nociones de identidad étnica en el contexto caribeño del archipiélago de San Andrés permite una lectura detallada de los procesos de sincretismo y aculturación a los que la comunidad raizal de las islas es expuesta en su cotidianidad como consecuencia de las dinámicas económicas y sociales que excluyen y marginalizan su propia etnicidad. Con la política homogeneizadora del Gobierno Colombiano durante la década de 1910, "que tenía como meta la uniformidad cultural mediante la estrategia de asimilación del Archipiélago al continente a costa de su identidad cultural" (Botero Mejía, 2007, p. 277) las tensiones sociales, económicas y culturales en la isla, marcaron diferencias importantes en las dinámicas de sus comunidades. En Canclini (1999), se explica cómo estos 
efectos homogeneizadores del proceso globalizador son producto "de múltiples movimientos, en parte contradictorios, con resultados abiertos, que implican diversas conexiones "local-global" y "local-local" (Canclini, 1999, p. 34).

En este contexto, estas conexiones entre lo global y lo local se intensifican a partir de la declaración de la apertura económica de las islas a mediados del siglo XX y se reflejan en la proliferación de imaginarios sociales entorno a la negación y desconocimiento de la propia identidad étnica de la comunidad raizal, como resultado de la influencia extranjera en la construcción de una cotidianidad que excluye a los isleños en su propio territorio. Al respecto, Valtolina (2019), resalta las implicaciones directas del entorno y sus dinámicas sociales en la construcción del autoconcepto e identidad de quienes se desarrollan como miembros de una comunidad considerada minoría en un contexto culturalmente adverso. Si bien sus apreciaciones parten del análisis alrededor de la identidad étnica en población migrante, el aporte a la discusión sobre el legado cultural del Archipiélago se fundamenta en la coincidencia de la condición de exclusión en ambas comunidades; la migrante y la raizal, por lo que el efecto de la centralidad étnica del hombre extranjero durante el proceso de formación identitaria de los raizales se ve reflejado en el incremento de prácticas como el alisado del pelo afro y el blanqueamiento de la piel.

Los niños "de color" que crecen en una población predominantemente blanca y que inevitablemente prestan gran atención, desde los primeros años de vida, a su diferencia respecto a la mayoría de los habitantes y consecuentemente se convierten en los más sensibles a la hora de darse cuenta no sólo de las diferencias somáticas, sino también de las eventuales características que suelen ser asociadas a la cultura de los blancos. (Valtolina, 2019, p. 33)

Por otra parte, la política y el discurso de colombianización instaurados en las islas a finales del siglo XIX encontraron en el modelo escolar positivista gestionado por las congregaciones religiosas capuchinas, la plataforma adecuada para imponer el uso del español y la práctica del catolicismo como lengua y religión oficial en todo el territorio del Archipiélago. Las facultades otorgadas por la institucionalidad colombiana a la orden religiosa en 1954, le permitió al Prefecto Fray Gaspar de Orijuela ordenar que "las tres escuelas bautistas y las dos adventistas de la isla cerraran por no seguir el plan de estudios del Ministerio de Educación, y por tener el inglés como medio de instrucción” (Ross, 2007, p. 22); esta medida afectaría a seiscientos niños raizales y se convertiría en uno de los desencadenantes del distanciamiento étnico que se intensificó en las décadas posteriores con la llegada de la apertura comercial (Mantilla, 2011), cuyo beneficio no se reflejaría en el estímulo del crecimiento comercial para los isleños, sino en el favorecimiento de condiciones para el aumento de inversionistas extranjeros; en su mayoría, de la Colombia continental.

Como consecuencia de estas diferencias históricas y su naturaleza independiente, los isleños no se sentirían atraídos ante la idea de integrarse laboralmente a la infraestructura turística y comercial que se desarrollaría en el Archipiélago; hasta ese momento, la posesión de tierras había representado gran parte de los bienes 
de la comunidad raizal por lo que, en la etapa inicial de la apertura comercial, su idiosincrasia, junto con la discriminación de la que eran víctimas, influyeron en la exclusión de las actividades económicas derivadas del turismo y el comercio transnacional. Sin embargo, "como los isleños no tenían mucho dinero o ingresos en efectivo, las demandas de impuestos sobre la tierra a menudo no podían satisfacerse salvo mediante la venta de tierras" (Ross, 2007) por lo que de forma paulatina y bajo el estímulo de un currículo escolar orientado hacia el fortalecimiento de la producción, la fuerza laboral isleña se condicionó en favor de los inversionistas.

Con la llegada de la escuela activa a principios del siglo XX, el contexto educativo nacional y su ideal escolarizante es descrito por Guerrero V. (2002) como un proceso formador orientado hacia la capacitación operativa de ciudadanos que contribuirían a alcanzar la noción de desarrollo impuesta por la hegemonía extranjera. La idea de la escuela activa apuntaba a la formación de un ciudadano amante del trabajo, productivo, útil y saludable, valores que se relacionaban con la figura idealizada del hombre anglosajón en contraste con las características negativas atribuidas a las comunidades latinas y afro (Guerrero V.,2002) (Sáenz, Saldarriaga y Ospina, 1997). Esto se debería en gran medida, a la incursión técnica y financiera de los Estados Unidos a finales de la década de 1940 y al "modelo de desarrollo en vigencia en aquel país y en los de Europa Occidental. Que, adoptado con ciego optimismo por los Gobiernos de América Latina, iría a ser aplicado sin vacilación ni ajustes" (Beltrán, 2005, p. 14), lo cual, se reflejaría en el uso de la escuela como instrumento de centralización política, hecho característico durante los procesos de modernización de los estados (Clemente, 1991).

Según Torres (1985), para Freire la discusión alrededor de estas tensiones se aborda desde lo que denomina cultura burguesa y cultura popular; desde allí, amplía y categoriza todas las expresiones "que van desde el lenguaje mismo, el discurso, la sintaxis, la tonalidad de la voz, [...] las formas de defenderse de la dominación, las mañas de los oprimidos que incluso pueden llegar a ser orgánicas y las festividades" (Torres, 1985, p. 44), como producto de la cultura popular; pero al mismo tiempo, reflexiona sobre la influencia que la cultura burguesa dominante ejerce sobre sus dinámicas. "Ningún exponente de la clase dominante dice que su gusto es el de su clase. Por el contrario, dice y cree que es el todo de la sociedad, de la nación y no es verdad" (Torres, 1985, p. 43). Con la llegada de los medios de comunicación masiva a las islas caribeñas en la década de 1950, este discurso homogeneizador se amplificaría y cobraría mayor relevancia en la vida de los raizales quienes manifestarían que después de la llegada de la televisión, niños, niñas y jóvenes "prefieren ver novelas y películas extranjeras con contenidos violentos, que sentarse a escuchar cuentos. Pero también es cierto que los padres ya 'no tienen tiempo' para estar con sus hijos porque están trabajando" (Botero Mejía, 2007, p. 284).

Desde las perspectivas de la comunicación de Beltrán (2005); el abordaje de estas imposiciones tiene que ver con la implementación paulatina de un discurso que se consolida desde múltiples escenarios y forma parte del día a día de la comunidad raizal sanadresana por lo que incide en cada aspecto de la vida de los individuos que la componen. En consecuencia, el resultado de las políticas nacionalistas extendidas a 
través de la escuela y los medios reflejan el uso de la comunicación "como un proceso unidireccional (monológico) y vertical (impositivo) de transmisión de mensajes de fuentes activas a receptores pasivos sobre cuya conducta ellas ejercen así presión persuasiva para asegurar el logro de los efectos que buscan”(Beltrán, 2005, p. 20).

Sin embargo, las dinámicas socioculturales que surgen como consecuencia de estas políticas represoras tienden a estimular la proliferación de movimientos que reivindican la resistencia contrahegemónica; por lo que en las comunidades de isleños tomaron fuerza diversas manifestaciones como respuesta a los abusos del gobierno y al peligro potencial de la desaparición de su legado cultural. Desde el punto de vista político y diplomático, a través de la gestión en defensa de la cultura raizal adelantada por colectividades como el "Club Archipiélago Unido" durante las décadas de 1960 y 1970 en Bogotá (Clemente, 1991; Ross, 2007). Mientras que en lo cotidiano y desde las islas, por medio del trabajo de difusión cultural de las narradoras orales, quienes representan la contrapuesta educativa a un modelo funcionalista en el que no se reconoce su etnicidad. Estos esfuerzos por el rescate de la identidad étnica son entendidos como una herramienta a la que se recurre cuando dos o más culturas coexisten e interactúan en un contexto definido por relaciones de poder, "cuando siente malestar a la hora de tener que hacer frente a otra propuesta de otra identidad, con valores distintos de aquellos que el individuo ha asimilado en su proceso de socialización" (Valtolina, 2019, p. 36)

La lectura de Pomare y Dittman (2000) sobre las coyunturas socioculturales en el contexto sanandresano y la necesidad de materiales escritos propios para la construcción de un programa etnoeducativo intercultural en las escuelas de la comunidad, plantea la idea de una educación diversa, contrahegemónica e identitaria, en la que se valoran los procesos formativos y las pedagogías locales a través de las cuales se transmiten los saberes y conocimientos de la cultura raizal. Es decir, se conceptualiza la etnoeducación como un "puente que une la cultura y la escuela" (Sánchez Castellón, 2018,p. 169) y la oralidad como su eje etnopedagogíco; por esta razón, el valor en la obra de Pomare se manifiesta a través del ejercicio comunicativo en prácticas como el libro viajero, un cuaderno itinerante en el que los mayores en cada familia consignan las historias de su niñez. De esta manera, la estrategia permite el aporte colectivo a la memoria raizal, lo que además "de construir un compendio por la cultura tradicional, permite que los isleños se reconozcan como autores de sus propias historias y fomenta la conversación entre adultos, jóvenes y niños" (Patiño, 2011, p. 127).

La proximidad estructural entre el libro viajero y el modelo comunicativo EMIREC (Cloutier, 2001) refiere a la participación alternada de los actores comunicativos desde el desempeño de una doble función como emisores y receptores, que en el contexto del libro viajero se traduce en la posibilidad para las familias raizales de contar sus propias historias, pero también en la de conocer las de sus vecinos en favor de la construcción articulada e integradora de su propia identidad cultural. En consecuencia, se difiere de las nociones hegemónicas de comunicación en la medida en que la implementación de políticas impositivas "reduce la comunicación a transmisión de informaciones - corresponde a una sociedad concebida como poder: unos pocos emisores imponiéndose a una mayoría de receptores" mientras 
que "la segunda, a una sociedad construida como comunidad democrática" (Kaplún, 2010). Para Freire (1987), las dinámicas que se desprenden de este modelo comunicativo favorecen el intercambio alternado de contenidos que, por el contrario de las nociones de la educación bancaria, estimula y enriquece el diálogo entre los actores. "La educación debe comenzar por la superación de la contradicción educador-educando. Debe fundarse en la conciliación de sus polos, de tal manera que ambos se hagan, simultáneamente, educadores y educandos" (Freire, 1987, p. 52).

La oralidad como instrumento de cohesión social en los isleños, hace que sus dinámicas interpersonales se desarrollen de forma directa, "cara a cara. El chisme, la opinión de los vecinos y la charla cotidiana son de suma importancia para mantener esa red tanto de información como de conocimiento. Red magnificada por la pequeñez del territorio" (Ratter, 2001); al respecto, las consideraciones en torno a la conformación de comunidades motivadas por el deseo colectivo de aprender ofrecen una aproximación a las dinámicas en que se desarrolla el intercambio de conocimiento práctico y la construcción de saberes colaborativos en el libro viajero. La idea de sociedad desescolarizada (Illich, 1975) plantea el desbordamiento de las aulas de clase como único entorno de aprendizaje y reconoce en el mundo un escenario de formación permanente; además, valora las experiencias del individuo y lo concibe como formador y formado, lo que estimula el intercambio horizontal de información y favorece la construcción colectiva de saberes a partir de la historicidad de cada uno de sus miembros.

Conforme los ciudadanos tengan nuevas posibilidades de elección, nuevas posibilidades de aprendizaje, su disposición a buscar directivos debiera aumentar. Podemos contar con que experimentarán más hondamente tanto su propia independencia como su necesidad de guía. Conforme estés liberados de la manipulación por parte de terceros, debieran aprender a beneficiarse de la disciplina que otros han adquirido durante toda su vida. El desescolarizar la educación debiera más bien aumentar, y no ahogar, la búsqueda de hombres de sabiduría práctica que estuviesen dispuestos a apoyar al recién llegado en su aventura educativa. (Illich, 1975, p. 134)

Desde las perspectivas de la narración oral, el valor que se le otorga a las experiencias coincide con la función del comunicador popular que "no consiste sólo ni tanto en transmitir nuevos conocimientos, sino sobre todo en presentar a la comunidad popular experiencias que ésta ya está viviendo y darle instrumentos para decodificarlas, interpretarlas, analizarlas, llegar a comprender sus causas" (Kaplún y García, 1985, p. 175) por lo que el trabajo investigativo de Pomare al compilar "descripciones, narraciones y explicaciones sobre aspectos tradicionales de la cultura del Archipiélago" (Patiño, 2011, p. 124), conjuga la tradición y la oralidad raizal con la atemporalidad de la palabra escrita para ofrecer una aproximación a su propia identidad anglo-afrocaribeña; de la que Patiño (2011), en retoma de Parson (1985), resalta: "el apellido Pomare lo llevan los descendientes de los esclavos que pertenecían a un cultivador francés de ese apellido, quien estuvo cultivando algodón en la isla a principios del siglo XIX" (Patiño, 2011, p. 123). 
Si bien en Leipold (2002), el testimonio de la comunidad raizal respecto a su pasado africano evidencia un distanciamiento cultural; "Todavía los Native Islanders más viejos saben poco sobre sus raíces africanas, o no les gusta hablar de estos" (Leipold, 2002, p. 101), el aporte cultural de Pomare a la construcción identitaria de la isla, representa a la mujer raizal como símbolo de resistencia a la interacción histórico-hegemónica entre culturas provenientes de diferentes territorios y rescata el valor de la palabra hablada como parte de su herencia africana desde la construcción de un discurso propio. De esta manera, la música, la danza, la pesca y demás actividades tradicionales que hacen parte de los saberes raizales se divulgan a través de diversas expresiones como los concerts, que son descritos por Pomare en el texto de Patiño (2011) como obras de teatro "en las que se permitía entre escenas otras expresiones artísticas, cómo, por ejemplo: canto, bailes, danzas, narraciones de historias, cuentos, chistes, entre otras" (Patiño, 2011, p. 126). Los orígenes de estos espacios de expresión están relacionados con las presentaciones artísticas que le eran impuestas a los esclavos para diversión de sus amos blancos. La idea de un esclavo interpretando con su cuerpo bailes de salón europeos, "parecía a los blancos cómico porque él era negro; asimismo, del punto de vista del negro, la representación del baile podía significar sin embargo una parodia de los blancos, que divertía a su vez a los africanos" (Leipold, 2002, p. 61).

La popularidad de espacios similares posteriores respondió, además, al efecto histórico de invisibilizad que la hegemonía en vigencia ejerció sobre la herencia africana de los raizales a través de medidas como la prohibición de los tambores en las islas durante la colonia. "Para dominar, el dominador no tiene otro camino sino negar a las masas populares la praxis verdadera. Negarles el derecho de decir su palabra, de pensar correctamente" (Kaplún, 2010, p. 112) primero con el tambor y después con la imposición del idioma español en el archipiélago. Sin embargo, a pesar de la negación del legado africano en los isleños, es su propia oralidad la que los conecta con las antiguas formas de comunicación y transmisión de conocimientos.

La publicación de Nacimiento, vida y muerte de un sanandresano (Pomare y Dittman, 2000) repasa el ciclo de vida raizal desde "una relación temporal muy estrecha con la religión, la tierra, y el mundo de los espíritus” (Pomare y Dittman, 2000, p. 18). El ciclo inicia con el nacimiento del niño y describe prácticas como el vínculo del recién nacido a su árbol de la vida o el barrer de puertas hacia dentro durante nueve días para evitar que el alma del niño abandone su cuerpo, lo que se relaciona con los meses de gestación en el vientre de la madre durante la etapa previa al nacimiento y es representado también durante el ritual funerario isleño mediante una ceremonia que se extiende durante nueve días, antes del regreso a casa del alma de quien haya muerto. La conexión de esta práctica con el legado esclavo de la colonia deriva de las antiguas ceremonias en las plantaciones denominadas wakes, que "duraban nueve noches, y creaban en la comunidad de los esclavos una fuerte sensación de grupo contra el dominio blanco, de cuya esfera de poder el muerto finalmente estaba rescatado" (Leipold, 2002, p. 60), pues según las creencias de los esclavos, el alma del muerto dejaba su cuerpo para regresar a África. Generaciones 
posteriores mantendrían la creencia que se traduciría en la expresión "It time fi guo hom - es hora de volver a casa, cuando ya estaban cansados de este mundo, cuando sus cuerpos no resistían más" (Pomare y Dittman, 2000, p. 65).

El efecto de la tradición oral raizal determina la manera como los isleños se relacionan y comprenden el mundo además de identificarlos con su ancestro africano en la medida en que la palabra hablada se transformó, para ellos, en sinónimo de identidad; por esta razón, del aporte de Pomare y Dittman (2000) se desprende la idea de una educación bilingüe y el estímulo de la práctica escritural en las islas como testimonio de la historia de su comunidad. "Estamos trabajando con las tres escuelas bautistas para imponer un sistema de escribir en nuestro Creole. ${ }_{j} E s$ algo que nosotros tenemos que desarrollar, nadie va a hacer lo para nosotros! ¡Vamos a mover adelante este proceso y estaremos orgulloso de esto!"(Leipold,2002, p. 115). La amenaza histórica a la cultura raizal y su herencia africana transformó la cosmovisión de los isleños durante la colonia y la colombianización. "Sin embargo, dicha cultura está completamente viva y arraigada en su gente a medida que cambia e intercambia, se reconstruye y se transforma constantemente, pues ninguna cultura es estática” (Botero Mejía, 2007, p. 284).

\section{CONSIDERACIONES FINALES}

El recorrido planteado alrededor del esfuerzo histórico de las narradoras orales por salvaguardar la herencia cultural y ancestral de la comunidad raizal en el Árchipielago de San Andrés, Providencia y Santa Catalina, permite determinar que a pesar de la implementación de politicas cuyos efectos se padecen desde inicios del proceso constituyente de su territorio; el pasado africano fortalece desde su oralidad el valor identitario de los raizales en la medida en que este legado es hoy sinonimo de resistencia frente a las driectricez en las que no se reconoce su propia naturaleza y que con el devenir del tiempo han socabado sus valores tradicionales.

Los liderazgos contemporanos que derivan de la memoria histórica compilada por las narradoras orales, representan una contribución a la reinvindicación de la identidad de la mujer raizal desde las perspectivas feministas y decoloniales en cuanto el valor de su labor etnoformativa, que se vincula a las diferentes expresiones de resistencia utilizadas por estas mujeres para resguardar su herencia; resignifican los imaginarios construidos alrededor del rol de la mujer afro y estimulan el interés en las nuevas generaciones por replicar estas prácticas en el contexto de su comunidad.

La lectura sobre las secuelas del período esclavista en la comunidad sanandresana evidencia que las prácticas de imposición cultural se extendieron más allá de la época colonial, por lo que la narrativa oral creole se constituye desde el rol de la mujer raizal como garante de la conservación de su memoria e identidad aún en un escenario como el actual; permeado por los medios tradicionales de comunicación e interconectado a través de las nuevas tecnologías.

El efecto de las mediaciones en la población de las islas posterior a la llegada de la radio, la prensa y la televisión se manifiestó en la adopción de las nuevas creencias y comportamientos que se masificaron en el territorio. Sin embargo, como 
resultado del contraste entre la conformación de un ecosistema mediático desde las hegemonías durante la segunda mitad del siglo pasado y la democratización de los entornos versatiles de las TIC en la actualidad, se configura un nuevo escenario para el que el aporte etnoeducativo de la oralidad raizal constituye un elemento articulable con las dinámicas mediáticas de las plataformas contemporáneas de comunicación.

En síntesis, resulta necesario destacar que la potencial y paulatina implementación de políticas integrales fundadas en el respeto por las tradiciones ancestrales de la comunidad raizal, resultarán posibles gracias a la visibilización de las dinámicas sincréticas y transculturales que, a lo largo de su propia historia, la conducen hacia la mediatización popular de la tradición oral raizal en el Archipiélago.

\section{REFERENCIAS}

AROCHA, J. Afropacífico caribeño. 2000. Dissertación (Maestría en Estudios Caribeños)-Universidad Nacional de Colombia, Caribe, 2000. Disponible en: http://www. scielo.org.co/scieloOrg/php/reflinks.php?refpid=S0120-4807200700020001400002\&ln $\mathrm{g}=$ en\&pid=S0120-48072007000200014. Acceso en: 1 mar. 2020.

BELTRÁN, L. R. La Comunicación para el desarrollo en Latinoamerica: Un recuento de medio siglo. In: CONGRESO PANAMERICANO DE LA COMUNICACIÓN, 3., 2006, Anagramas. Anales [...]. Buenos Aires, Argentina: Universidad de Buenos Aires, 2005. p. 53-76. Disponible en: https://dialnet.unirioja.es/servlet/ articulo? codigo $=5181393$. Acceso en: 7 oct. 2019.

BOTERO MEJÍA, J. Oralidad y escritura en la isla de San Andrés. Universitas Humanistica, Bogotá, v. 64, n. 64, p. 275-289, jun. 2007. Disponible en: https:// revistas.javeriana.edu.co/index.php/univhumanistica/article/view/2235. Acceso en: 20 nov. 2019.

BUTIÉRREZ, L. U. I. S. Hacia el horizonte comprensivo de la corporeidad: una transición entre los enfoques de Husserl y Heidegger. Agora, v. 39, n. 2, p. 79-106, 2020. https://doi.org/10.15304/ag.39.2.5977

CANCLINI, N. G. La globalización e interculturalidad narrada por los antropólogos. Maguaré, Bogotá,v. 14, p. 19-41. en. 1999. Disponible en: https://revistas.unal.edu.co/ index.php/maguare/article/view/11134. Acceso en: 10 mar. 2020.

CASTELLA. Las siete partidas del Rey don Alfonso el Sabio. España: Imprenta Real, 1807.

CHAVES, M. E. La mujer esclava y sus estrategias de libertad en el mundo hispano colonial de fines del siglo XVIII. 1998. Disponible en: https://gupea.ub.gu.se/ bitstream/2077/3175/1/anales_1_chaves.pdf. Acceso en: 22 nov. 2019.

CLEMENTE, I. Educación, política educativa y conflicto político cultural en San Andrés y Providencia, 1886-1980. Bogotá: Departamento de Historia, Universidad de los Andes, 1991. Disponible en: http://www.scielo.org.co/scielo.php?script=sci_ nlinks\&ref=000100\&pid=S0486-6525201100020000400008\&lng=en. Acceso en: 12 mar. 2020. 
CLOUTIER, J. Petit traité de communication: EMEREC: à l'heure des technologies numériques. Quebec: Éditions Carte blanche Télémédiatique, 2001.

COLOMBIA. Decreto no 2966BIS. (1953). Presidencia de la República de Colombia. Diario Oficial, año XC, n. 28367, 10 dic. 1953. Disponible en: http://www.suin-juriscol. gov.co/viewDocument.asp?ruta=Decretos/1504760. Acceso en: 17 sep. 2019.

CUEVAS, M.P.F. La construcción de la identidad en la modernidad. Divulgare Boletín Científico de la Escuela Superior de Actopan, v. 8, n. 15, p. 55-58, 2021. https://doi. org/10.29057/esa.v8i15.6432

DE LA ROCHA PENNA, M. La mujer negra en la formación de la sociedad brasileña y la devoción a Yemanjá: estudio preliminar. In: SERNA MORENO, J; DÍAZ ARROYO, V. (org.). Historia de America Latina y el Caribe. México: Universidad Nacional Autónoma de México, 2014. p. 229.

FREIRE, P. Pedagogía del oprimido. 36. ed. México: Siglo XXI, 1987.

GUERRERO V., D. G. La imposición de modelos pedagógicos en Colombia - siglo XX. Estudios Latinoamericanos, Pasto, n.10-11,p.21-32,31 mar.2002.Disponible en: https:// revistas.udenar.edu.co/index.php/rceilat/article/view/3253. Acceso en: 25 nov. 2019.

HERRERA, G. Örikí para las negras viejas de antes. In: JARAMILLO, M. M.; ORTÍZ, L. (org.). Hijas del Muntu: biografías críticas de mujeres afrodescendientes de América Latina. Bogotá: Editorial Panamericana, 2011. p. 35-45.

ILLICH, I. La sociedad desescolarizada. México: Barral, 1975.

JARAMILlO, M.; ORTIZ, L. Hijas del Muntu: Biografías críticas de mujeres afrodescendientes de América Latina. Bogotá: Panamericana, 2011.

KAPLÚN, M. Una pedagogía de la comunicación. Madrid: Ediciones de la Torre, 2010. v. 10.

KAPLÚN, M.; GARCÍA, M. El comunicador popular. Quito: Ciespal, 1985.

LEIPOLD, C. Our native thing: estudio sobre la imagen histórica de los sanandresanos en el mar Caribe Colombiano. 2002. 247f. Tesis (Doctorado en Ciencias Históricas y Filosofía) - Universität de Marburg, Alemania, 2002. Disponible en: http://babel. banrepcultural.org/cdm/ref/collection/p17054coll23/id/1005/. Acceso en: 26 nov. 2019 . LEÓN,M.D.L.Á.A. Papel reproductivo y productivo de las mujeres esclavas en Costa Rica en el siglo XVIII. Revista de Historia, n. 57-58, p. 135-161, 2008. Disponible en: https:// www.revistas.una.ac.cr/index.php/historia/article/view/1757. Acceso en: 17 sep. 2019.

LIPSCHUTZ, A. E1 problema racial en la conquista de América. 2. ed. Santiago de Chile: Andrés Bello, 1975.

MANTILLA, S. Narcotráfico, violencia y crisis social en el Caribe insular colombiano: El caso de la isla de San Andrés en el contexto del Gran Caribe. Estudios Políticos, Medellín, n. 38, p. 39-67, 2011. Disponible en: http://aprendeenlinea.udea.edu.co/ revistas/index.php/estudiospoliticos/article/view/10015. Acceso en: 26 nov. 2019. 
MEISEL-ROCA, A. et al. Economía y medio ambiente del archipiélago de San Andrés, Providencia y Santa Catalina. Bogotá: Libros Banco de la República, 2016. MONTOYA, R. A. "Piezas de Indias" en una frontera esclavista novohispana.: Una mirada a la corporeidad del esclavo africano en el San Luis Potosí del siglo XVII. Historia 2.0: Conocimiento Histórico en Clave Digital, n. 9, p. 83-102, 2015. Disponible en: https://dialnet.unirioja.es/servlet/articulo?codigo=5156333. Acceso en: 13 ago. 2019.

MORLACHETTI, A. Amas de cría y nodrizas. In: JARAMILLO, M. M; ORTÍZ, L. (org.). Hijas del Muntu: biografías críticas de mujeres afrodescendientes de América Latina. Bogotá: Editorial Panamericana, 2011. p. 43-46.

PARSON, J. San Andrés y Providencia: una geografía histórica de las islas colombianas del mar Caribe Occidental. 3. ed. Bogotá: Ancora, 1985.

PATIÑO, A. Lolia Pomare Myles: puente entre la palabra antigua y la nueva. In: JARAMILLO, M. M; ORTÍZ, L. (org.). Hijas del Muntu: biografías críticas de mujeres afrodescendientes de América Latina. Bogotá: Editorial Panamericana, 2011. p. 121-133.

PÉREZ-BRIGNOLI,H. Aculturación, transculturación, mestizaje: metáforas y espejos en la historiografía latinoamericana. Cuadernos de Literatura, Bogotá, v. 21, n. 41, p. 96-113, 2017. https://doi.org/10.11144/Javeriana.cl21-41.atmm

POMARE, L.; DITTMAN, M. L. Nacimiento, vida y muerte de un sanandresano. Colombia: Ministerio de Cultura, 2000.

RATTER, B. M. Redes caribes: San Andrés y Providencia y las islas Cayman: entre la integración económica mundial y la autonomía cultural regional. San Andrés: Universidad Nacional de Colombia, Instituto de Estudios Caribeños, 2001.

RICOEUR. P. Sí mismo como otro sexto estudio: el sí y la identidad narrativa. México: Siglo XXI, 2006.

ROSS, J. Routes for roots: entering the 21st century in San Andrés Island, Colombia. Caribbean Studies, Puerto Rico, v. 35, n. 1, p. 3-36, 2007. Disponible en: https://www. jstor.org/stable/25613090. Acceso en: 18 nov. 2019.

SAÉNZ, J.; SALDARRIAGA, O.; OSPINA, A. Mirar la infancia: pedagogía, moral y modernidad en Colombia. Bogotá: Colciencias, 1997.

SÁNCHEZ CASTELLÓN, E. B. Etnoeducación y prácticas interculturales para saberes otros. Utopia y Praxis Latinoamericana, v. 23 n. 83, p. 166-181, 2018. https:// doi-org.ezproxy.uniminuto.edu/10.5281/zenodo. 1439065

TORRES, R. M. Educación popular: un encuentro con Paulo Freire. Crefal, v. 8, n. 1-2, p. 117-153. ene. 1985. Disponible en: https://www.crefal.org/rieda/index. php?option=com_content\&view=article\&id=238\&Itemid=224. Acceso en: 10 jul. 2019. 
VALTOLINA, G. Procesos de aculturación, identidad étnica y menores migrantes. Revista Interdisciplinar Mobilidade Humana, Brasília, v. 27, n. 55, p. 31-47, abr. 2019. https://doi.org/10.1590/1980-85852503880005503

XOLOCOTZI, Á.; GIBU, R. Fenomenología del cuerpo y hermenéutica de la corporeidad. Madrid: Plaza y Valdes, 2014.

YABRUDY, J. Discriminación étnica e ingresos en la Isla de San Andrés, Colombia. Revista de Economía del Rosario, Cartagena, v. 14, n. 2, p. 229-261, jul. 2011. Disponible en: https://revistas.urosario.edu.co/index.php/economia/article/view/2159. Acceso en: 5 nov. 2019.

\section{SOBRE EL AUTOR}

Diego Fernando Peña Garnica es magister en educación e investigador de la Corporación Universitaria Minuto de Dios (Colombia). Profesor de la misma institución.

E-mail: diego.pena.g@uniminuto.edu

Conflictos de intereses: $\mathrm{El}$ autor declara que no tiene ningún interés comercial o asociativo que represente un conflicto de intereses en relación con el manuscrito.

Financiación: El estudio no recibió financiación.

Recibido el 22 de mayo de 2020 Aprobado el 2 de marzo de 2021 